\title{
Bottom-up honeycomb top layer for light outcoupling enhancement in blue organic light emitting diodes
}

\author{
A. Bertrand ${ }^{\mathrm{a}}$, F. Dumur ${ }^{\mathrm{b}, \mathrm{c}}$, M. Mruczkiewicz ${ }^{\mathrm{b}, \mathrm{d}}$, M. Perrin ${ }^{\mathrm{d}}$, C. Lartigau-Dagron ${ }^{\mathrm{a}}$, A. Bousquet $^{\mathrm{a}}$, \\ L. Vignau ${ }^{\mathrm{c}}$, L. Billon ${ }^{\mathrm{a}, *}, \mathrm{~S}$. Fasquel ${ }^{\mathrm{c}, * *}$ \\ a IPREM, Équipe de Physique et Chimie des Polymères, CNRS UMR 5254, Université de Pau et des Pays de l'Adour, Hélioparc, 2 Avenue du Président Angot, 64053, Pau, \\ France \\ b Univ. Bordeaux, IMS, CNRS UMR 5218, F-33400, Talence, France \\ ${ }^{c}$ Aix Marseille Univ, CNRS, Institut de Chimie Radicalaire ICR, UMR 7273, F-13397, Marseille, France \\ d Laboratoire Ondes et Matière d'Aquitaine LOMA, Université Bordeaux, CNRS, UMR 5798, 33405, Talence, France
}

\section{A R T I C L E I N F O}

\section{Keywords:}

Breath figure

Blue OLEDs

Light outcoupling

Photonic Crystal

External Quantum Efficiency

\begin{abstract}
A B S T R A C T
Self-organized honeycomb (HC) polymer films were fabricated as a bottom-up assembly and deposited onto glass substrates in order to create extraction layers for blue OLEDs. Relying on the fast and tunable "Breath Figure" process, HC films were prepared on a minute time-scale and incorporated onto OLED devices, either through direct bottom-up formation onto the OLED substrates or through an original and convenient peeling/transfer method. Two types of HC films differing in period and morphology were prepared, and eventually led to an EQE improvement of $25 \%$ measured on an OLED whose emitter molecules are oriented parallel to the plane, using a vapor deposition at room temperature. Additionally, we have modeled the optical characteristics of the HC films, leaning on the fact they are periodic and very regular. This 3D optical model, complemented by a 1D electrical model to determine the Emission Zone Profile (EZP), predicts that the photonic films we fabricated are able to enhance up to $29 \%$ the EQE, and opens perspectives for a better design of extraction layers.
\end{abstract}

\section{Introduction}

During the past decade, OLEDs have attracted a great deal of in terest due to their potential applications in flat panel displays and lighting [1 4]. If highly emissive light emitting materials can be now routinely designed, one of the main issues for OLEDs remains the en hancement of the light outcoupling efficiency. Indeed, only $20 \%$ of the light initially electro generated can escape from the front side of the transparent substrate to form a useful emission, the rest of the photons being immediately trapped into lossy guided modes [5 8] of the me tallo dielectric structure that eventually dissipate as heat [9]. Over the years, numerous methods have been explored to solve the problem of poor light outcoupling efficiency.

A recent approach [10] has shown that the control of molecular orientation in the emissive layer (EML) during the fabrication is pos sible, and that it permits to favor dipole emission in the direction normal to the stack plane. This is done to avoid light coupling to guided modes and favor extraction. However, it is known that the dipole emission depends on its electromagnetic environment [11,12], so that one cannot be sure a priori that using a parallel oriented emitter would be enough to solve the problem of light trapping, as initially thought see Fig. 15 of [10].

Another solution, independent of the emitter orientation is to use Bragg gratings [13 24] and low index grids [25], which can help ex tracting the ITO/organic modes. Glass modes can also be extracted through substrate surface patterning [21,26 35]. Numerous textures have been successfully employed for light outcoupling, including micro lens arrays [26 30], pyramides [31 33], nanopillars [34]. Polymeric coatings are of particular interest for such strategy, since they can be easily processed into suitable shapes owing to their typically accessible melting point and good solubility. However, such shapes are typically obtained by costly top down techniques such as photolithography or soft lithography, requiring specially designed templates or UV etching capabilities. A simple two step method based on the low cost "breath figure" (BF) bottom up process [35] was recently used to fabricate a light extracting polydimethylsiloxane (PDMS) micro lens layer by templating. Originally described by François et al. [36] and extensively studied since then [37 39], BF templating is a self assembly method that relies on the fast drying of a polymer solution under a humid air flow. The evaporation induced surface cooling triggers the

\footnotetext{
* Corresponding author.

** Corresponding author.

E-mail addresses: laurent.billon@univ-pau.fr (L. Billon), sophie.fasquel@ims-bordeaux.fr (S. Fasquel).
} 
condensation of water droplets that self organize into close packed hexagonal arrays. Upon complete evaporation of the solvent, a porous honeycomb structure is obtained that is reminiscent of the water dro plets template. BF templating offers many advantages over conven tional lithographic methods used to produce ordered microstructures: the process is fast (typically of the order of a minute), cheap and up scalable $[40,41]$, it does not require the manufacturing of any tailor made template, the water template is effortlessly removed through natural evaporation, and the pore size can be tuned in some extent by varying experimental conditions such as humidity, temperature, or air flow [37]. Whereas HC derived micro lens arrays proved to be efficient for light extraction, we aimed at simplifying further the OLED texturing by directly using the HC films as light extraction layer, thus avoiding the additional molding step of the micro lens design [35]. HC films were readily prepared by the $\mathrm{BF}$ method from anion terminated, poly styrene based materials. In particular a block copolymer containing a small elastomeric block of poly ( $n$ butyl acrylate) (PnBuA) allowed to obtain crack free HC films, that could be peeled off through water floating. This methodology allows the recovery of self supported HC films that can be easily transferred onto the substrate of interest. We investigated the outcoupling efficiency of two HC films differing in pore size and layer structure, to demonstrate both theoretically and experi mentally that such inexpensive texturing strategy can significantly improve OLED performances. Note that such comparison between theory and experiment is made possible by the fact the fabricated layers are very regular (at the difference with disordered extraction layers [42]).

\section{Experimental section}

\subsection{Materials}

$N$ (2 Methylpropyl) $N$ (1 diethylphosphono 2,2 dimethylpropyl) $O$ (2 carboxylprop 2 yl) hydroxylamine initiator (so called BlocBuilder", 99\%) and $N$ tert butyl $N$ (1 diethylphosphono 2,2 dimethylpropyl) nitroxide (SG1, 88.4\%) were kindly provided by Arkema. Styrene and $n$ butyl acrylate $(n \mathrm{BuA})$ monomers were purchased from Aldrich and were filtered prior to use by passing through a column of basic alu minum oxide to remove radical inhibitors. All materials used for the devices fabrication were purchased from Lumtec with the best purity available and used as received.

\subsection{Characterization}

${ }^{1} \mathrm{H}$ NMR spectra were recorded on a Bruker $400 \mathrm{MHz}$ spectrometer at $25{ }^{\circ} \mathrm{C}$ using $\mathrm{CDCl}_{3}$ as solvent. Polymers were analyzed with a Steric Exclusion Chromatography (SEC) apparatus running in THF at $30{ }^{\circ} \mathrm{C}$ (flow rate: $1 \mathrm{~mL} / \mathrm{min}$ ) equipped with a Viscotek VE 5200 automatic injector, a pre column and two columns (Styragels HR 5E and 4E), a Viscotek VE3580 refractive index detector, and a Wyatt Heleos II MALLS detector. Scanning electron microscopy (SEM) images were obtained with a HIROX SH 3000 using a $10 \mathrm{kV}$ accelerating voltage. SEM samples were metallized with $10 \mathrm{~nm}$ of gold using a Denton Vacuum DESK V sputter coater. ITO substrates were treated with a Jelight 42220 UVO cleaner. The electroluminescence (EL) spectra, CIE coordinates, current voltage and luminance voltage characteristics of the OLED devices were recorded with an External Quantum Efficiency Measurement System (model C9920 12) of Hamamatsu Photonics K.K.

\subsection{Synthesis of polymer materials}

Synthesis of polystyrene homopolymer (PS). In a $50 \mathrm{~mL}$ round bottom flask, $57.2 \mathrm{mg}(0.15 \mathrm{mmol})$ of Blocbuilder were dissolved in $6 \mathrm{~g}$ $(58 \mathrm{mmol})$ of styrene. The flask was sealed with a septum and degassed by bubbling nitrogen for $30 \mathrm{~min}$. The polymerization was carried out in an oil bath at $110{ }^{\circ} \mathrm{C}$ for $6 \mathrm{~h}$. The reaction was stopped by plunging the flask into liquid nitrogen and opening to air. Conversion was estimated by analyzing an aliquot of the obtained mixture by ${ }^{1} \mathrm{H}$ NMR, weighting the integral of vinyl protons of the monomer (5.3 $5.9 \mathrm{ppm})$ and the integral of aromatic protons of both the monomer and the polymer (7.5 $6.4 \mathrm{ppm}$ ). The polymer was isolated by precipitating first in me thanol, then in basic hydroalcoholic solution (9:1 v:v ethanol:water at $\mathrm{pH}$ 9), and dried under vacuum at $40{ }^{\circ} \mathrm{C}$ during $24 \mathrm{~h}$, yielding a white powder.

Synthesis of poly ( $n$ butyl acrylate) block polystyrene (PnBuA $b$ PS). Synthesis of PnBuA macroinitiator (PnBuA SG1): in a $50 \mathrm{~mL}$ round bottom flask, $500 \mathrm{mg}$ (1.3 mmol) of Blocbuilder and $76 \mathrm{mg}$ of SG1 $(0.23 \mathrm{mmol})$, both provided by Arkema, were dissolved in $5 \mathrm{~g}$ ( $40 \mathrm{mmol}$ ) of $n \mathrm{BuA}$.

Compared to the styrene polymerization previously described, an extra quantity of SG1 radical was needed to control the reaction be cause of the very fast propagation rate of acrylic monomers $[43,44]$. This prevents a too fast, uncontrolled polymerization (and safety issues due to the exothermic reaction). The flask was sealed with a septum and degassed by bubbling nitrogen for $45 \mathrm{~min}$. The polymerization was carried out in an oil bath at $110{ }^{\circ} \mathrm{C}$ for $1 \mathrm{~h} 30$. The reaction was stopped by plunging the flask into liquid nitrogen and opening to air. Conver sion was estimated by analyzing an aliquot of the obtained mixture by ${ }^{1} \mathrm{H}$ NMR, weighting the integral of vinyl protons of the monomer (5.7 $6.5 \mathrm{ppm}$ ) and the integral of methylene protons of both the monomer and the polymer (4.3 $3.8 \mathrm{ppm})$. The polymer was isolated by precipitating twice in a methanol/water mixture (7:3 v:v), and dried under vacuum at room temperature during $24 \mathrm{~h}$, yielding a colorless oily liquid. The molecular weight was estimated by ${ }^{1} \mathrm{H}$ NMR from re lative integration of the nitroxide end group protons $(\mathrm{N}-\mathrm{CH}-\mathrm{P}=\mathrm{O}$, $1 \mathrm{H}, \delta=3.23 .3 \mathrm{ppm}$ ) and the methylene group of the polymer ( $\mathrm{COO}-\mathrm{CH}_{2}-, 2 \mathrm{nH}, \delta=3.94 .1 \mathrm{ppm}$ ).

Synthesis of PnBuA b PS: the purified PnBuA SG1 was subsequently used as macroinitiator for the nitroxide mediated polymerization of styrene. In a $50 \mathrm{~mL}$ round bottom flask, $64 \mathrm{mg}(0.057 \mathrm{mmol})$ of PnBuA SG1 were dissolved in $3 \mathrm{~g}(29 \mathrm{mmol})$ of styrene. The flask was sealed with a septum and degassed by bubbling nitrogen for $30 \mathrm{~min}$. The polymerization was carried out in an oil bath at $115{ }^{\circ} \mathrm{C}$ for $7 \mathrm{~h}$. The reaction was stopped by plunging the flask into liquid nitrogen and opening to air. Conversion was estimated by analyzing an aliquot of the obtained mixture by ${ }^{1} \mathrm{H}$ NMR, weighting the integral of vinyl protons of the monomer (5.3 $5.9 \mathrm{ppm}$ ) and the integral of aromatic protons of both the monomer and the polymer (7.5 $6.4 \mathrm{ppm})$. The polymer was isolated by precipitating first in methanol, then in basic hydroalcoholic solution (9:1 v:v ethanol:water at $\mathrm{pH} 9$ ), and dried under vacuum at $40{ }^{\circ} \mathrm{C}$ during $24 \mathrm{~h}$, yielding a white powder. The molar mass of the PS block (and thus the molar mass of the PnBuA b PS copolymer) was estimated by ${ }^{1} \mathrm{H}$ NMR from relative integration of the PS aromatic protons (ArH, $5 \mathrm{nH}, \delta=6.37 .2 \mathrm{ppm}$ ) and the PnBuA methylene protons ( $\mathrm{COO}-\mathrm{CH}_{2}-, 2 \mathrm{nH}, \delta=3.94 .1 \mathrm{ppm}$ ).

\subsection{Fabrication of honeycomb film through the "breath figure" process}

The honeycomb films were obtained on $1.5 \times 1.5 \mathrm{~cm}^{2}$ indium tin oxide (ITO)/glass substrates (Visiontek Systems Ltd, thickness of $160 \mathrm{~nm}, 11 \Omega / \mathrm{sq}$ ) preliminarily cleaned by sonicating $10 \mathrm{~min}$ in acetone, then $10 \mathrm{~min}$ in isopropanol. The ITO side was ultimately cleaned by a $20 \mathrm{~min}$ exposure to a UV ozone plasma. The breath figure process was carried out in a spin coating chamber used as a confined environment. Ambient humidity was between 45 and 55\%, and tem perature between 20 and $23{ }^{\circ} \mathrm{C}$. In a typical procedure, the polymer was dissolved in carbon disulfide $\left(\mathrm{CS}_{2}\right)$ at the desired concentration, and a defined volume of the polymer solution was cast on the substrate. A vertical stream of humid air ( $2 \mathrm{~L} / \mathrm{min}, 8090 \%$ humidity, obtained by bubbling air into water) was then applied through a hole in the spin coater cover. PS honeycomb films (HC1) were obtained by spreading $40 \mu \mathrm{L}$ of PS solution $\left(10 \mathrm{~g} / \mathrm{L}\right.$ in $\left.\mathrm{CS}_{2}\right)$ on the glass side of glass/ITO 
Method 1:

Direct patterning

Method 2:

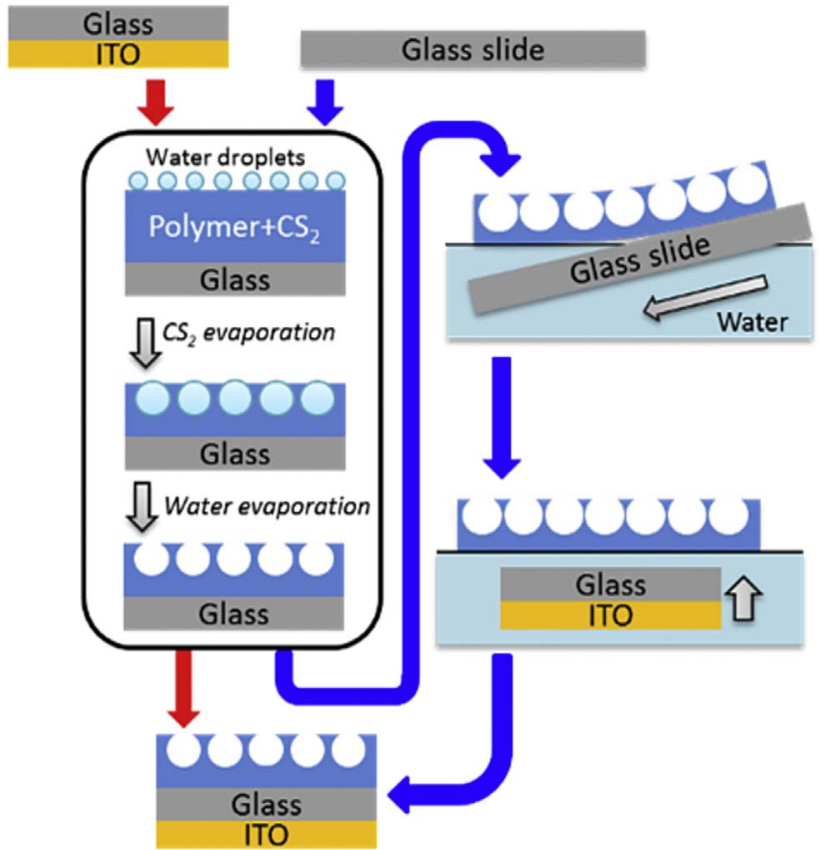

Fig. 1. Schematic representation of HC fabrication methods 1 and 2 (for HC1 and HC2 respectively).

substrates $\left(2.25 \mathrm{~cm}^{2}\right)$ (Fig. 1). As the pore size and pore ordering tend to vary from the center to the edges of the square substrate, we found that a slow rotating motion of the sample $(30 \mathrm{rpm})$ reduces such variations, thus providing good pore size homogeneity on the major part of HC1. PnBuA b PS honeycomb films (HC2) were prepared by casting $250 \mu \mathrm{L}$ of a dilute polymer solution $\left(0.5 \mathrm{~g} / \mathrm{L}\right.$ in $\left.\mathrm{CS}_{2}\right)$ on a microscopy glass slide. Good pore size homogeneity was obtained on a large surface $\left(\sim 68 \mathrm{~cm}^{2}\right)$ without the help of substrate rotation. After $45 \mathrm{~s}$, the newly formed honeycomb films were peeled off their substrates by slowly immersing the glass slide in a petri dish filled with distilled water, keeping a high incidence angle. This procedure has been described previously [45]. The floating films were then recovered onto the glass side of glass/ITO substrates (Fig. 1). The excess water was removed with absorbing paper and the HC covered OLED substrates were al lowed to dry. Eventually strong films were obtained that can be easily manipulated and allowing the deposition of further layers.

\subsection{Device fabrication}

OLEDs were fabricated onto HC covered and untreated ITO glass substrates with sheet resistance of $1012 \Omega$ /sq. Organic layers were sequentially deposited onto the ITO substrate at a rate of $24 \AA$ ss under secondary vacuum. Aluminum cathode was evaporated through a shadow mask by thermal evaporation.

\section{Results and discussion}

\subsection{Polymer synthesis}

Two different HC structured films were investigated as light ex traction layers. They were produced by the BF process from carbox ylate terminated polystyrene (PS) and poly ( $n$ butyl acrylate) block polystyrene block copolymer (PnBuA $b$ PS), respectively HC1 and HC2, both synthesized by nitroxide mediated controlled free radical poly merization (NMP) [46] (Fig. 2, Table 1). The use of the Blocbuilder ${ }^{\circ}$ initiator allows the straightforward incorporation of a carboxylic acid
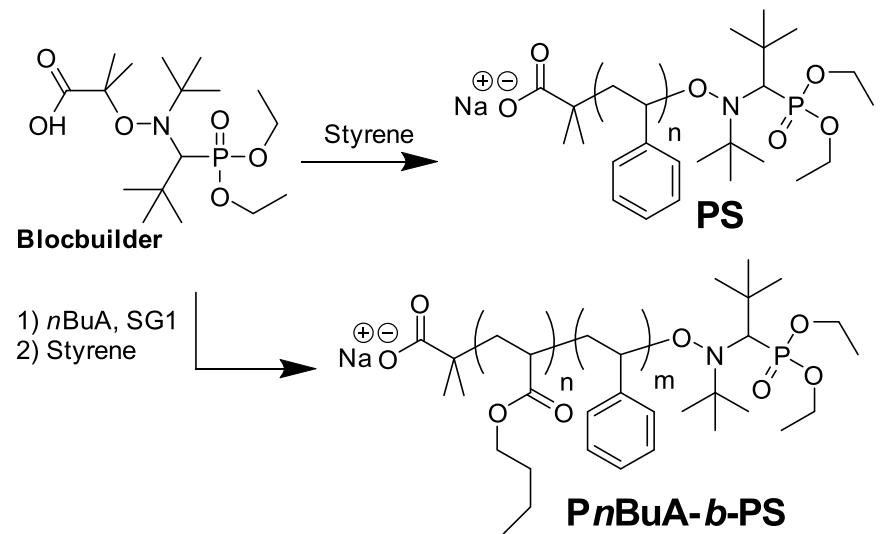

Fig. 2. Synthesis of PS and PnBuA-b-PS polymers employed for the fabrication of honeycomb films $\mathrm{HC} 1$ and $\mathrm{HC} 2$ respectively.

Table 1

Characteristics of PS and PnBuA-b-PS polymers.

\begin{tabular}{llll}
\hline Polymer & $M n_{\text {RMN }}(\mathrm{g} / \mathrm{mol})^{\mathrm{a}}$ & $M \mathrm{n}_{\text {SEC }}(\mathrm{g} / \mathrm{mol})^{\mathrm{c}}$ & $\Xi^{\mathrm{c}}$ \\
\hline PS & 18700 & 16500 & 1.08 \\
PnBuA-b-PS & $815-41800^{\mathrm{b}}$ & 43900 & 1.05 \\
\hline
\end{tabular}

${ }^{\text {a }}$ Not included: $381.45 \mathrm{~g} / \mathrm{mol}$ for Blocbuilder ${ }^{\circ}$.

${ }^{\mathrm{b}} \mathrm{P} n \mathrm{BuA}$ and PS blocks, respectively.

${ }^{c}$ Evaluated by SEC/MALLS in THF at $30{ }^{\circ} \mathrm{C}$ using dn/dc values of 0.185 (PS) and 0.183 (PnBuA-b-PS).

end group, further converted into a carboxylate by precipitation of the polymer into a basic hydroalcoholic solution. Such ionic end group provides better pore ordering during the BF process, by stabilizing the polymer/water droplets interface and thus limiting undesirable coa lescence [47].

Here, it is worth mentioning that the breath figure process can be combined with amphiphilic [48], coil coil [49], and rod coil [50] block copolymer nanophase segregation to elaborate hierarchically structured honeycomb porous films by the control of concomitant and interacting self organization processes occurring in time at different length scales. Indeed, copolymer ordering at nanometer length scale was described with respect to the ordering of micron sized pores [48 51]. However, no nanophase segregation is expected from the block copolymer (PnBuA $b$ PS) in the present work, given the low volume fraction in PnBuA ( 2\%).

\subsection{Honeycomb film fabrication}

All the HC films exhibited the expected iridescence due to light interaction with periodic microstructures [48] (Fig. 3). The PS HC films (HC1) were obtained from a $10 \mathrm{~g} / \mathrm{L}$ solution evenly spread on the glass side of $1.5 \times 1.5 \mathrm{~cm}^{2}$ glass/ITO substrates, and appear hazy, with some cracks attributed to the brittleness of PS (thermoplastic polymer with a glass transition temperature $\mathrm{Tg}$ of $100{ }^{\circ} \mathrm{C}$ ). The procedure took about $1 \mathrm{~min}$. The apparent surface pore diameter was estimated to about $1.2 \mu \mathrm{m}$ by SEM (Fig. 3), although areas near the substrate edges ex hibited smaller pore size (down to $1 \mu \mathrm{m}$ ). Cross sectional SEM imaging of a fractured sample revealed that the pores have a $1.7 \mu \mathrm{m}$ inner diameter, and often intersect each other.

We also employed a PnBuA b PS block copolymer that allowed producing more transparent $\mathrm{HC} 2$ films by BF, using a $0.5 \mathrm{~g} / \mathrm{L}$ solution (increasing the concentration above $12 \mathrm{~g} / \mathrm{L}$ yielded HC of lower quality, and no HC at all above $5 \mathrm{~g} / \mathrm{L}$ ). Surprisingly, HC2 films could not be obtained directly on the square OLED substrates, whereas they could be produced on large areas using microscopy glass slide as sub strate. Differences in surface energy and/or thermal conduction may 

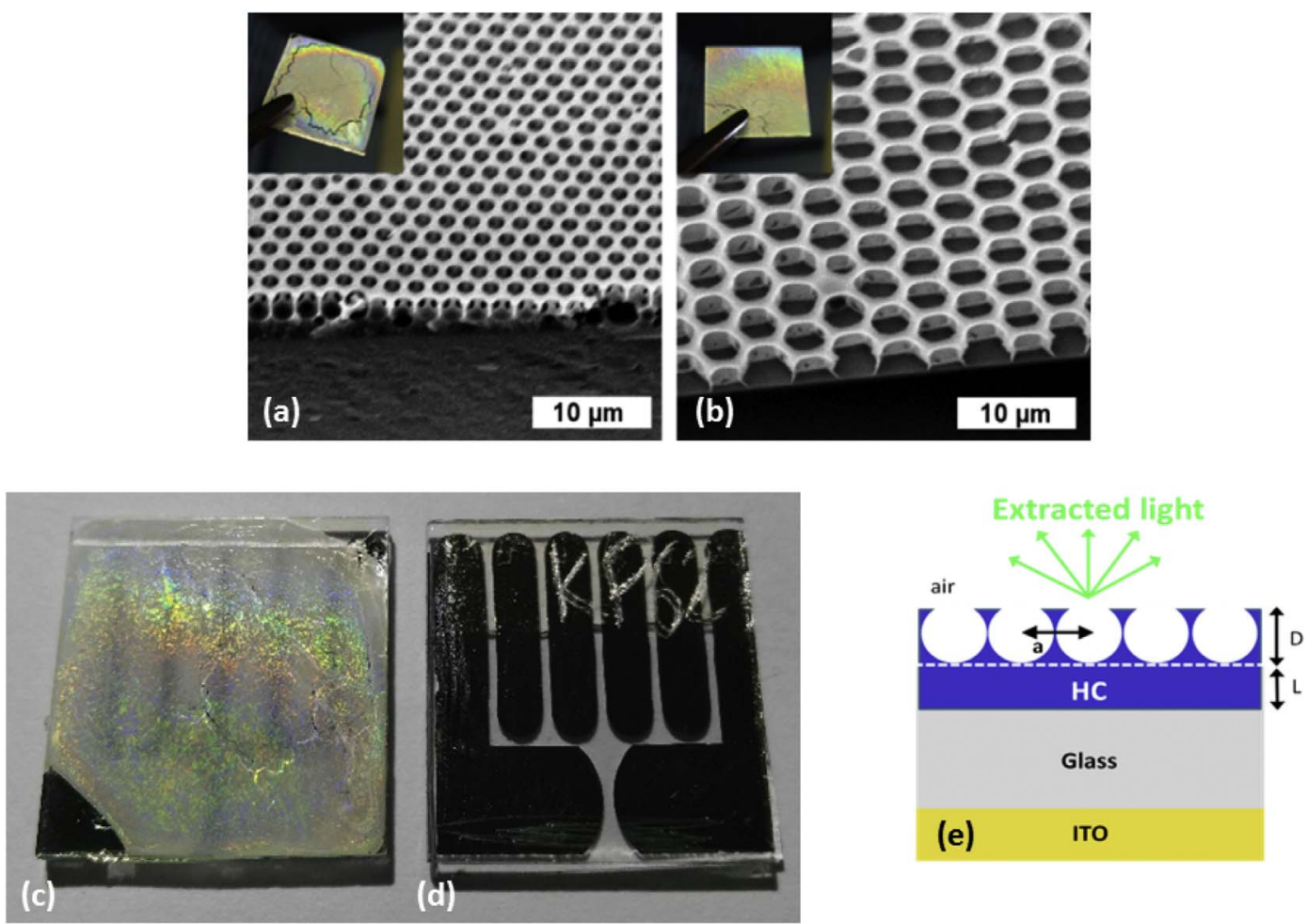

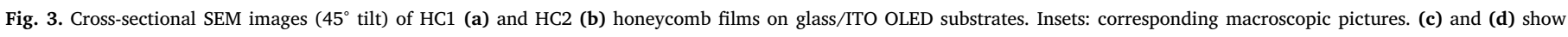

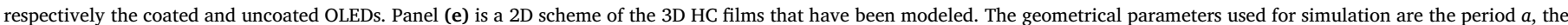

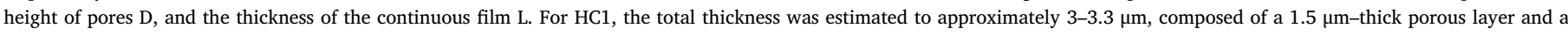

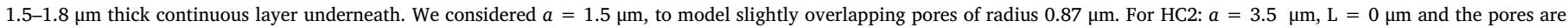
cylindrical.

account for this substrate dependent behavior. Nonetheless, we were able to peel the films off their substrates and transfer them onto OLED substrates using a simple water floating method. The HC fabrication is slightly lengthened (about $3 \mathrm{~min}$ ) compared to the direct procedure used for HC1. The nearly absence of cracks in the HC2 films attributed to the soft PnBuA block (low glass transition temperature $\mathrm{Tg}=-55{ }^{\circ} \mathrm{C}$ ) allowed carrying out the transfer without significant damage. The HC2 films being much larger than the $1.5 \mathrm{~cm} \times 1.5 \mathrm{~cm}$ portions effectively recovered, we concomitantly avoided the center/edge pore size dis crepancy observed for PS HC films (HC1) prepared directly on the square OLED substrates, although substrate rotation was a partial so lution in that case. It is worth noting that such indirect procedure can be of particular interest if the ultimate HC substrate is solvent sensitive (organic materials). The apparent surface pore diameter in HC2 film was estimated to about $3.43 .8 \mu \mathrm{m}$ by SEM (Fig. 3). Cross sectional imaging of a fractured sample revealed a $3.5 \mu \mathrm{m}$ inner diameter, with pores spanning the film thickness $(1.8 \mu \mathrm{m})$, without noticeable con tinuous sub layer.

\subsection{Fabrication of the HC patterned OLED}

Finally, the two HC films (HC1 and HC2) were investigated as light outcoupling layers for OLEDs. Low light outcoupling efficiency is an important limiting factor in the OLED technology, especially for blue devices that inherently suffer from lower photoluminescence quantum yields compared to the other colors [52 55]. Consequently, insertion of a light outcoupling layer on top of the glass substrate that could help to recover the lost waveguide modes of light is of special significance for blue OLEDs. For this study, a benchmark light emitting material i.e. 4,4' bis(4 (9H carbazol 9 yl)styryl)biphenyl (BsB4) has been selected as the blue fluorescent emitter $[56,57]$. To examine the light extraction ability of the honeycomb films deposited on the outer side of the glass substrate the following structures represented in Fig. 4 have been fabricated.

As represented in Fig. 4 (see left panel), the final device structure is the following: ITO was used as a transparent anode $/ \mathrm{MoO}_{3}(10 \mathrm{~nm})$ as a hole injecting material $/ \mathrm{MoO}_{3}: \mathrm{BsB} 4(20 \mathrm{wt} \%, 10 \mathrm{~nm})$ as the hole transport layer, BsB4 $(100 \mathrm{~nm})$ as the emission layer $(\mathrm{EML}) / 2,9 \mathrm{di}$ methyl 4,7 diphenyl 1,10 phenanthroline (BCP) $(10 \mathrm{~nm})$ as the hole blocking layer/tris(8 hydroxyquinolinato)aluminium ( $\left.\mathrm{Alq}_{3}\right)(30 \mathrm{~nm})$ as an electron transporting material/LiF $(1 \mathrm{~nm})$ as an electron injecting material and $\mathrm{Al}(80 \mathrm{~nm})$ as the cathode.

\subsection{Optical and electrical modeling}

In this section, we describe briefly the opto electrical model of the OLED. This latter relies on the assumption that the increase of EQE due to the presence of the extraction layer is only due to an increase of the outcoupled light, but not to a change of the Purcell factor (i.e. the rate of emission) of the emitting molecules. The corresponding multilayer structure (see Fig. 4) is caped with a 3D honeycomb structure denoted HC1 or HC2, which has been presented in section 2. The HC1 coating is made of truncated spherical pores of period $a=1.5 \mu \mathrm{m}$ and diameter $1.7 \mu \mathrm{m}$. Their height $\mathrm{D}$ is $1.5 \mu \mathrm{m}$, and they are arranged above a con tinuous PS layer of thickness $\mathrm{L}=1.5 \mu \mathrm{m}$ (see the scheme Fig. 3e). The second type of film HC2 has no continuous film $(L=0)$. Note that the shape of HC2 pores is quite different from that of HC1, as shown by the MEB pictures (see Fig. 3), where the HC2 profile is clearly more cy lindrical (we assumed perfectly cylindrical pores in the calculation, for HC2 film).

In such cases, Finite Element Method is a very convenient tool, as it permits to easily implement complex (e.g. overlapping) pores shapes and to compute the optical properties of photonic membranes [58]. We first compute the electromagnetic response to a plane wave excitation at a wavelength of $473 \mathrm{~nm}$, corresponding to the maximum of the EL spectrum. A single plane wave is sent on the photonic structure (i.e. the 

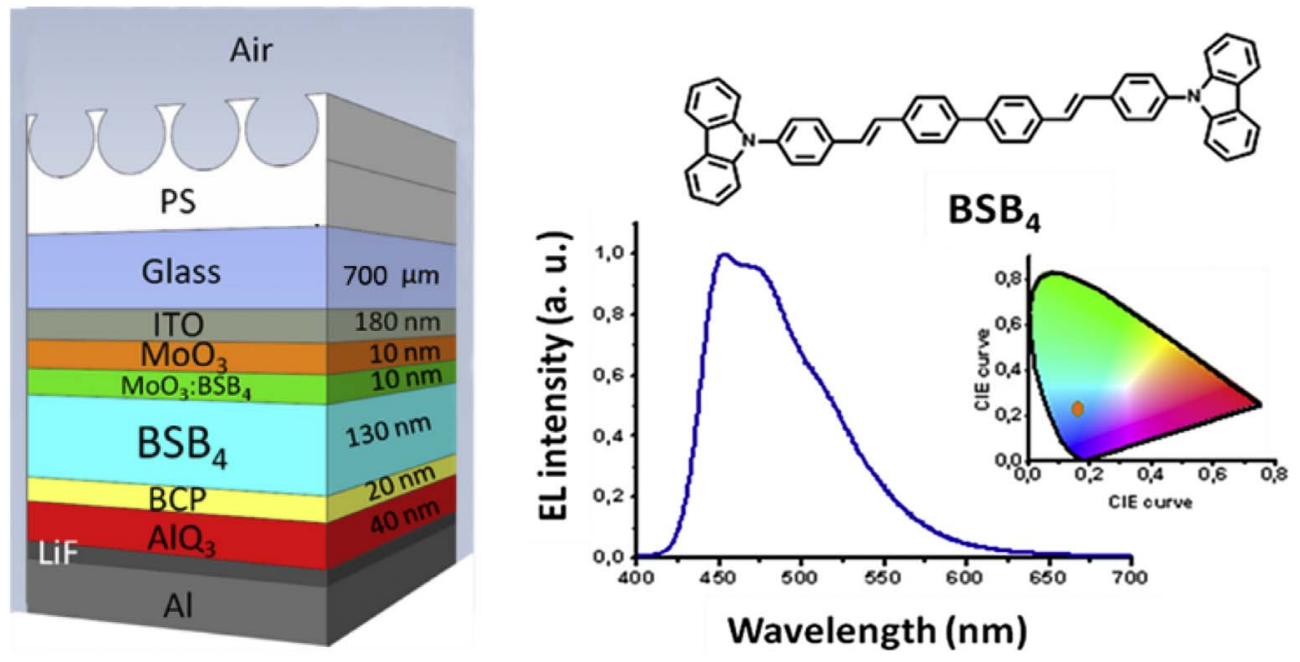

Fig. 4. (Left) Device structure of the blue multilayer OLED with the HC film deposited on the glass substrate and (Right) Chemical formula of the blue fluorescent emitter (BsB4) used to fabricate the device and the corresponding EL spectrum/CIE coordinates. (For interpretation of the references to colour in this figure legend, the reader is referred to the web version of this article.)

HC film), with a given polarization, and angle of incidence, and one eventually obtains the optical signature of the structured coating. Note that the recently developed formalism of Quasi Normal Mode expan sion [59] could be used advantageously in further works, to simplify the computation of the optical response of the photonic layer. Finite Ele ment calculations have been performed with COMSOL 5.2 software, taking into account the real and imaginary part of the refractive index of all the organic (and metallic) layers.

When one of the angles of incidence is varied, one clearly sees (Fig. 5, left axis) that some energy can be transmitted above the critical angle, $\theta c=\arcsin (1 / n) \sim 42^{\circ}$ where $\mathrm{n}=1.5$ is the glass refractive index , if a photonic extraction layer is used. This is due to the ex citation of photonic resonances, which permits light transmission at specific angles and wavelength, because of guided resonance effects $[60,61]$. They are responsible for the observed iridescence. However, with the extraction layer, slightly less energy is transmitted at small angles. Therefore, using a PC layer to increase the OLED EQE is meaningful only if the source emits some energy above the critical angle.

In practice, the direction of emission dramatically depends on the distance between the source and the metal electrode [62], as well as on the orientation of the molecular dipole [63], that governs its interaction with the local density of electromagnetic modes [59].

In the present case, the emitter (BsB4), vapor deposited at room temperature is preferentially oriented parallel to the stack planes [10]. We shall make this assumption in the model.
One can see on Fig. 5 a typical emission profile (right hand axis), for a dipole placed in the middle of the BsB4 layer, at $125 \mathrm{~nm}$ from the LiF/ $\mathrm{Al}$ cathode. If the source were punctual as it is the case for an OLED with thin EML the calculation of the transmission weighted by the dipole emission, see Fig. 5, could give an estimate of the extraction gain. However, in the present architecture, one need to consider many point sources in the EML, each of which emits many plane waves, that bounce back and forth in the substrate, between the $\mathrm{Al}$ coated and the Photonic Crystal (HC) coated surfaces [58].

In order to do so, one first computes the EQE gain assuming the dipole source is punctual and located at different positions in the EML (see Fig. 6). Then, this gain is weighted by the exciton distribution, computed from an electrical model of the OLED (see Fig. 7). Let us detail hereafter.

For each source location in the EML, we compute the emission profile in the thick glass substrate, and use the transmission function of the HC layers, and reference OLED, see Fig. 5, to compute the out coupled power with/without extraction layers. The outcoupling gain (i.e. the ratio of extracted power with/without extraction layers) is shown on Fig. 6. Both films have almost the same characteristics, except HC2 is slightly better (between $2 \%$ and $7 \%$, depending on emitter lo cation). For a point source close to the $\mathrm{BCP} / \mathrm{BsB} 4$ interface, emission is mostly along $\mathrm{z}$ axis, normal to the OLED stack see inset a. Only a small fraction of the light emitted in this region of EML couple to the guided modes. Accordingly, the PC film has no interesting effect there. We make the same remark when the dipole source is close to the BsB4/

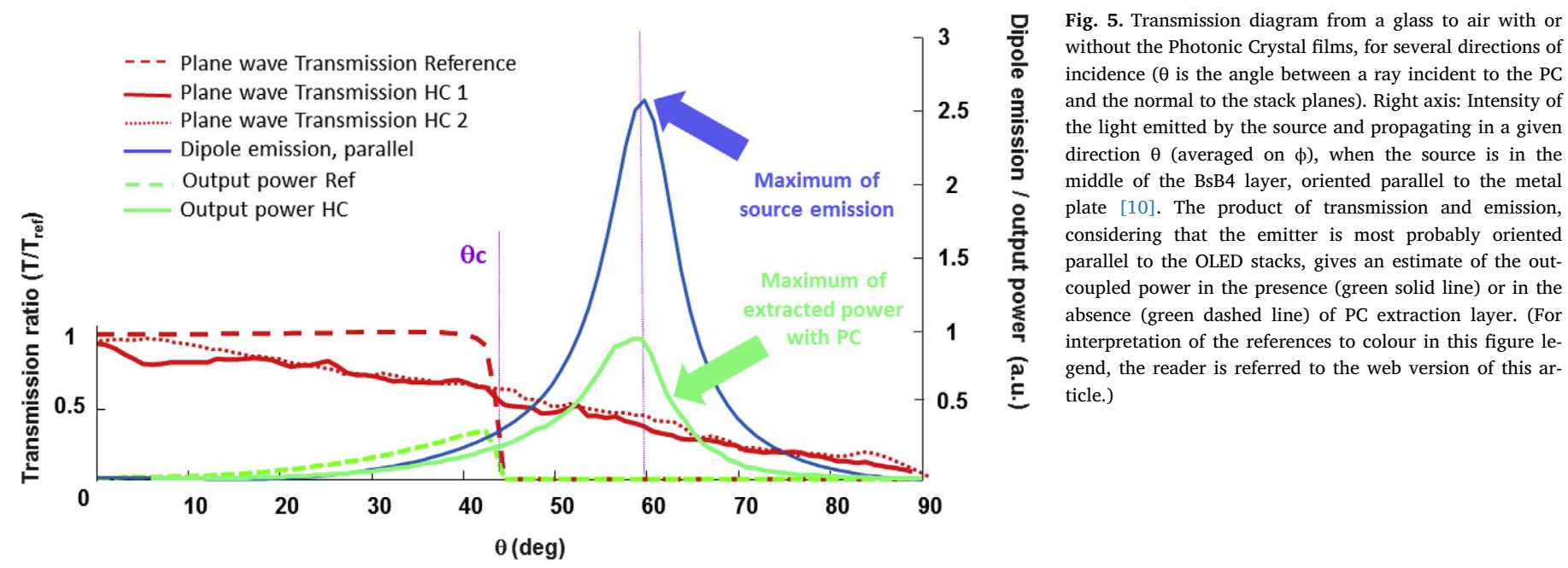




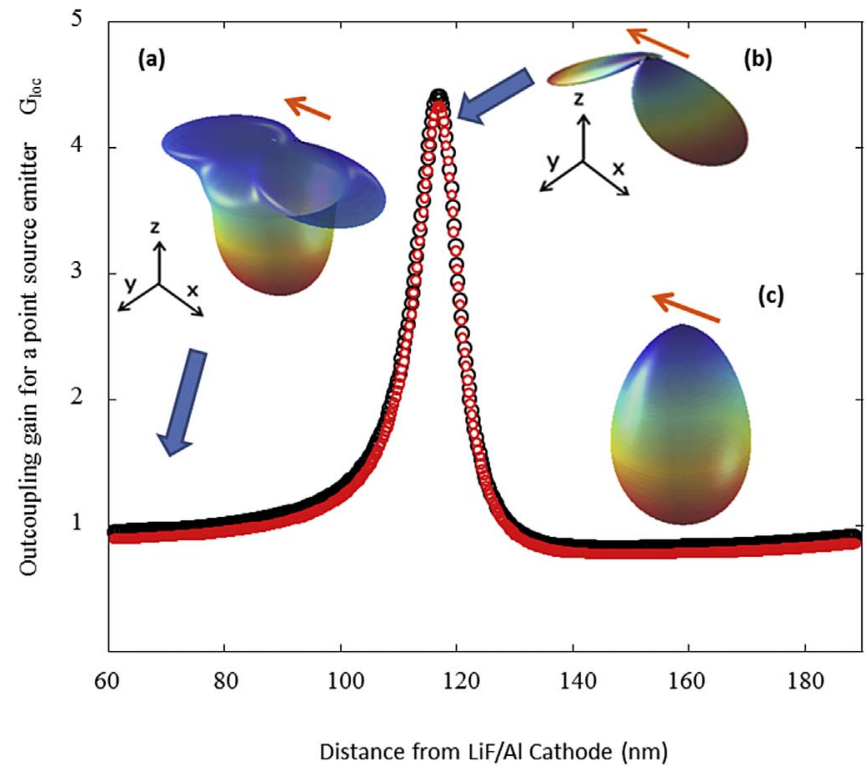

Fig. 6. Outcoupling gain for a point source emission placed at different location in the EML, when both HC1 film (small red circles), or HC2 film (larger black circles) are used. The insets shows the three-dimensional light emission profile in an infinitely thick layer of glass for the bare OLED (without the extraction film), when the source is (a) at $10 \mathrm{~nm}$ from the BCP/BsB4 interface, (b) at the center of BsB4 layer, (c) at $100 \mathrm{~nm}$ from the BCP/ $\mathrm{BsB} 4$ interface. (For interpretation of the references to colour in this figure legend, the reader is referred to the web version of this article.)

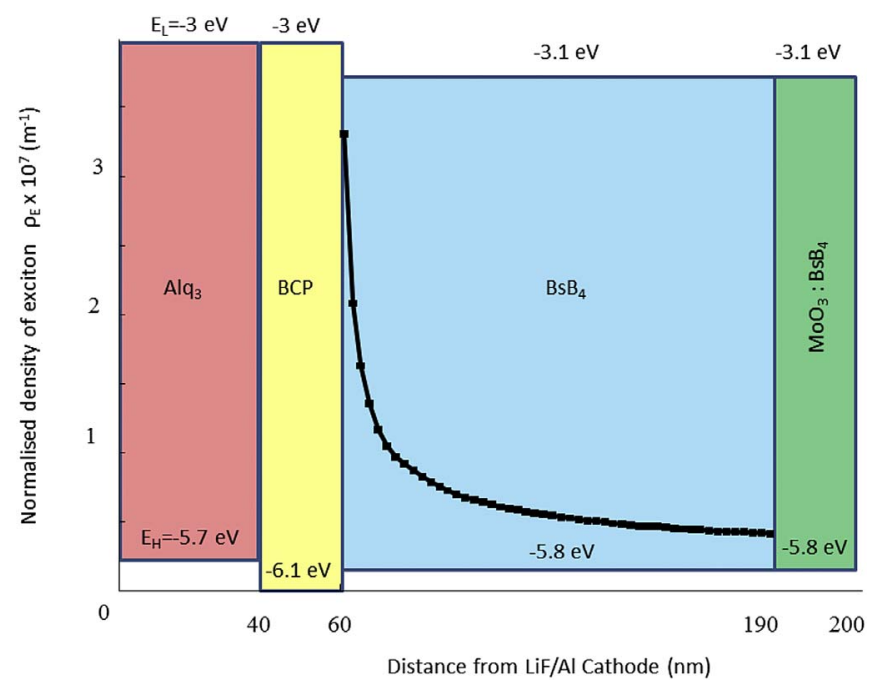

Fig. 7. Electrical scheme of the OLED. The exciton density in EML is the black curve with symbols. The HOMO/LUMO levels considered are indicated in each layer. The electrodes (not shown) are $\mathrm{ITO} / \mathrm{MoO}_{3}$ at anode (right-hand side), with a work function of $5.05 \mathrm{eV}$ [65], and $\mathrm{LiF} / \mathrm{Al}$ at cathode (left-hand side), with a work function of $-3 \mathrm{eV}$ [66]. A tension of $10 \mathrm{~V}$ at room temperature was considered. Note that the density is normalized so that $\int_{E M L} \rho_{E}=1$.

$\mathrm{MoO}_{3}: \mathrm{BsB} 4$ interface see inset c. However, the behavior we observe is very different for a source close to the middle of BsB4 layer see inset $b$. Most of the light emitted there propagates above the critical angle (see Fig. 5) and would remain trapped to guided substrate modes if there were no extraction layer. With the PC layers (whether HC1 or HC2), a large EQE gain of $450 \%$ can theoretically be reached, at this very specific source location.

This shows that even when molecular orientation favors OLED emission [10], the perturbation of the dipole source by its electro magnetic environment (mainly the interaction with the metallic cathode), can lead to light trapping, and would necessitate an extraction layer to improve EQE.

In order to evaluate the response of the whole OLED, and the effi ciency of the PC layer, we now need to know what is the distribution of dipole source in the EML, or Emission Zone Profile. In first works [58], some of us considered an idealized exciton distribution. To be more accurate, we use here a commercial solver, SETFOS [64] to make an electrical modeling of the OLED by solving the drift diffusion equation for electric charges when a voltage is applied.

To elaborate the electrical model, we took the HOMO/LUMO data from the literature $[67,68]$, as well as the work function of the $\mathrm{LiF} / \mathrm{Al}$ cathode [66] and the ITO/ $\mathrm{MoO}_{3}$ anode [65]. Electron mobility of $\mathrm{BsB}_{4}$ is $1.2 \mathrm{e} 8 \mathrm{~cm}^{2} / \mathrm{Vs}$ [67]. As we could not find data for hole mobility in BsB4, we tested that our results are practically unchanged upon taking a hole mobility between 1 e $5 \mathrm{~cm}^{2} / \mathrm{Vs}$ and 1 e $8 \mathrm{~cm}^{2} / \mathrm{Vs}$ for $\mathrm{BsB}_{4}$ (larger than electron's mobility). In the electron transport layer (ETL), made of $\mathrm{Alq}_{3}$, mobilities were assumed to be 1 e $5 \mathrm{~cm}^{2} /$ Vs for electrons and $1 \mathrm{e}$ $8 \mathrm{~cm}^{2} / \mathrm{Vs}$ for holes [68]. The Hole transport layer (HTL) is a blend of $\mathrm{MoO}_{3}$ and $\mathrm{BsB}_{4}$ that has been modeled as a doped $\mathrm{BsB}_{4}$ layer. The ac ceptor doping concentration was varied between $10^{13}$ and $10^{17} \mathrm{~cm}^{-3}$ with little effect on the exciton density in EML.

The results clearly show that excitons are preferentially located close to BCP/BsB4 interface, see Fig. 7. This is in agreement with the fact, that due to larger hole mobility (compared with electron's) in EML, excitons "accumulate" close to the ETL. However, a close look reveals the presence of a long tail of exciton density that extends over the whole EML. To be quantitative, we define the EQE gain as

$G_{E Q E}=\int_{E M L} G_{l o c}(x) \rho_{E}(x) d x$

Where the integral is taken on the width of the emissive layer, and involves the normalized exciton distribution $\rho_{E}(x)$, see Fig. 7, and the EQE gain for a point source, $G_{l o c}(x)$ when the recombination takes place at location $\mathrm{x}$, see Fig. 6.

Eventually we find an EQE gain of $29 \%$ for HC2 and $23 \%$ for HC1. These results are compared to the measurements in the next section.

\subsection{Opto electrical characterization of the HC patterned OLED}

Prior to further investigations and to determine the light extraction efficiency of the different $\mathrm{HC}$ films, electrical characteristics of both the pristine devices and HC patterned devices were examined.

As evidenced by a careful control of the OLED J V (current density/ voltage) curves which were similar with or without HC (Figure not shown), we estimate that the modification of the electroluminescence (EL) performance arises from the HC films.

As can be seen from Fig. 8, the External Quantum Efficiency (EQE) of OLEDs with structured outcoupling layers shows an enhancement of approximately $25 \%$ for HC2 based devices and 12\% for HC1 based OLEDs, both compared to the reference devices at a current density of $500 \mathrm{~mA} / \mathrm{cm}^{2}$. This improvement, observed over a wide range of current density, is interpreted to be due to the HC films that increase the ex traction of guided modes in the glass substrate.

Fig. 9, panel (a), represents the Luminance/Voltage (L V) curves of the reference device and devices bearing honey comb films HC1 (PS) and HC2 (PS PnBuA). The same trend as EQE enhancement of Fig. 8 can be deduced from the measurement of the luminance vs. voltage. Indeed, HC2 based devices achieved a luminance of $17000 \mathrm{~cd} / \mathrm{m}^{2}$ (at $13 \mathrm{~V}$ ), far the luminance determined for HC1 based devices $\left(7000 \mathrm{~cd} / \mathrm{m}^{2}\right)$ and the reference device $3600 \mathrm{~cd} / \mathrm{m}^{2}$ at the same voltage. Therefore, higher luminances at lower voltages could be obtained for the two devices comprising $\mathrm{HC} 1$ and $\mathrm{HC} 2$ as light outcoupling layers and these results are consistent with an extraction of photons trapped in the glass sub strate.

It was expected that HC2, with larger pore diameter, would give better results. Indeed, in this structure, more modes can be excited [69], what increases in particular the outcoupling of light above the critical 


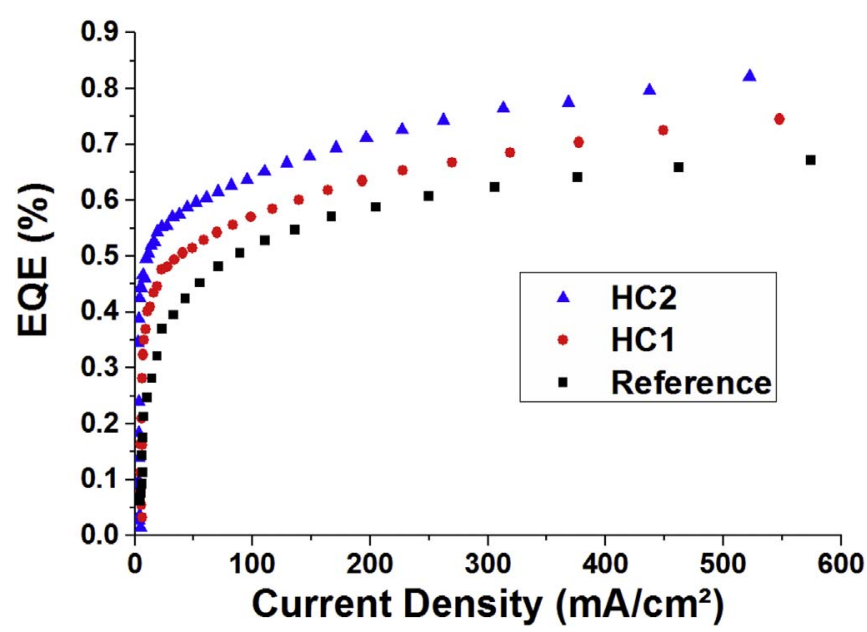

Fig. 8. External quantum efficiency (EQE, \%) vs. current density $\left(\mathrm{mA} / \mathrm{cm}^{2}\right)$ for the reference and devices bearing honeycomb coatings HC1 (PS) and HC2 (PS-PnBuA).

angle. We notice a good agreement between model and experiment for HC2, and some substantial difference, concerning HC1. This might come from the fact that there is residual absorption or diffusion (not taken into account in the model) in the continuous film below the PC, that is present in HC2, not in HC1. In particular, HC1 bears a milky, white color at naked eye, suggesting the presence of light diffusion in the continuous layer. This diffusion would enhance the coupling of light to the guided mode of the continuous film of higher index $(n=1.6)$, what we would like to avoid. In the future, it would be preferable to find techniques (as for HC2), were no continuous film appears.

These results show the strong insight of this rapid and cheap bottom up method compare to other methods with metal oxide nano honeycomb structured OLED based on the monolayer colloidal crystal (MCC) pattern of polystyrene spheres (PS) filled with thermally eva porated MoOx following by removal of the residual spheres with ad hesive tape [70], solution processed organic nano and micro materials [71], emissive layers with homogeneous molecular distribution of host and guest [72], orientation of the transition dipole moment of emitters [10], or other approaches [73] for fabricating high efficiency organic light emitting diodes.

To complete the experimental characterization of the electro optical properties of the HC patterned OLEDs, the electroluminescence spectra have been measured for each device types. EL characterization is of particular significance since the color of an OLED can be affected by the introduction of a pattern into such a multilayer architecture, as ob served when internal extractors are used $[18,74]$. Such color change is a very general feature (also true at the nanoscale [75]) caused by the modification of the density of states that can arise from the coupling between a resonator (here the OLED stack with or without Photonic Crystal) and an emitter.

Comparison of the outcoupled light for the two devices with that of the reference evidenced that neither the position nor the shape of the EL peak was strongly affected by the HC films (see Fig. 9, panel (b)).

A blue light peaking at $465 \mathrm{~nm}$ with a full width at half maximum (FWHM) of $69 \mathrm{~nm}$ was obtained. EL spectra of all devices barely changed over the whole voltage range, which is a sign that the spectrum of emission in the EML remains unaffected by the presence of HC films. This legitimates the hypothesis of our model, that the Purcell factor is unaffected by the Photonic Crystal layer.

\section{Conclusion}

Nowadays, tremendous efforts are made to improve the perfor mances of blue OLEDs. In this work, we have shown that microporous honeycomb (HC) polymer films can be used for this purpose, as an ef ficient external light outcoupling layer (up to $25 \%$ gain measured for EQE). Even in the case of an OLED with emitters oriented parallel to the planes, some region of the thick EML can emit photons that couple strongly to guided modes. In this case, it is interesting to add an ex ternal outcoupling layer. Note that the HC films are produced within a minute by the spontaneous condensation of water droplets at the sur face of a drying polymer solution, either directly on the OLED substrate or on a temporary substrate from which the HC film can be peeled off and transferred. Their very good regularity permits to use a model derived from the physics of photonic crystals to obtain their optical characteristics, that was combined with an electrical 1D model of the OLED, to obtain the Emission Zone Profile. Considering the versatility of the "breath figure" templating (pore size, regularity/randomness of pore network) and the flexibility provided by the new transfer ap proach, we believe this fast and inexpensive patterning strategy can be easily implemented in a wide variety of OLED devices or organic flex ible functional films. In particular, perspectives of higher gain, as pre dicted by theory, will be sought by optimizing both the morphology of the HC photonic films and the architecture of the OLED. In particular, comparison between model and experiment leads us to think that it is important to find the good synthesis to fabricate extraction layers with a continuous film as thin as possible.

\section{Acknowledgements}

This work was supported by public grants overseen by the French National Research Agency (ANR), (ANR 10 EQPX 28 01/Equipex ELORPrintTec, ANR 13 BS08 0003/PhotoLighT and ANR 10 EQPX 16 XYLOFOREST), and the Aquitaine Region, SMOLED project.
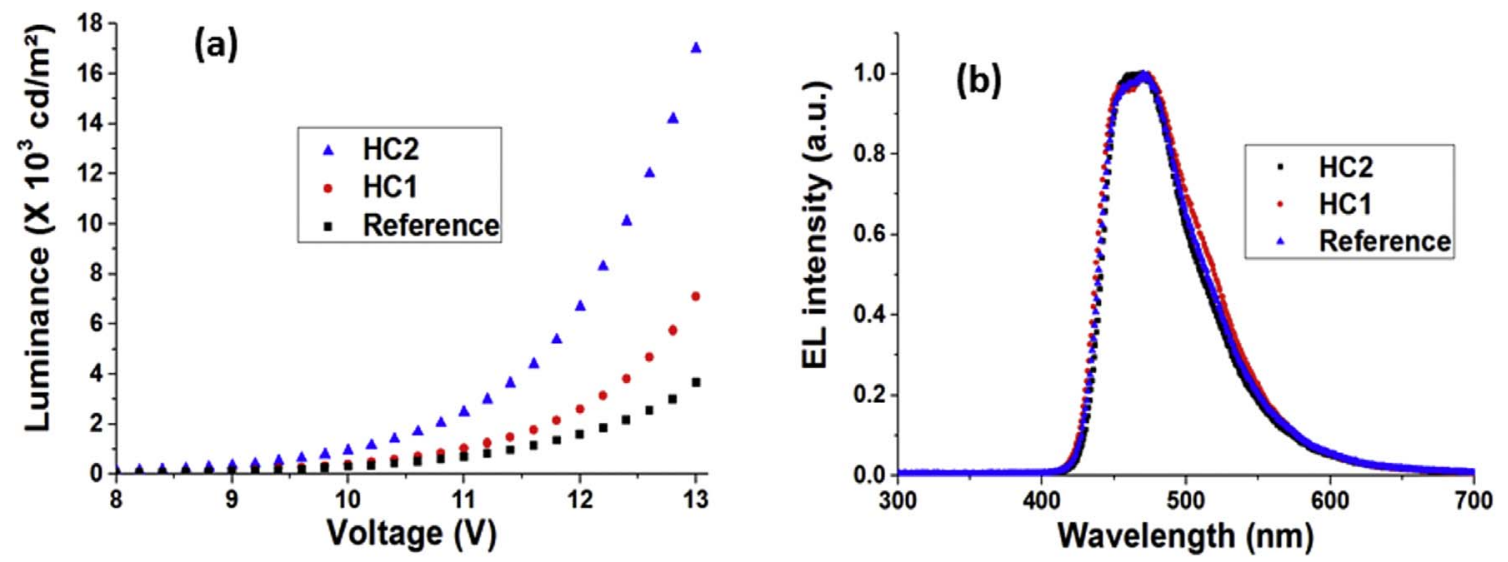

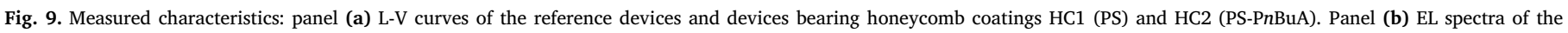
reference devices and devices bearing honeycomb coatings HC1 (PS) and HC2 (PS-PnBuA). 


\section{Perrin acknowledges Marc Tondusson for help on transmission measurements.}

\section{References}

[1] G. Schwartz, S. Reineke, T.C. Rosenow, K. Walzer, K. Leo, Adv. Funct. Mater. 19 (2009) 1319-1333.

[2] F. So, J. Kido, P. Burrows, MRS Bull. 33 (2008) 663-669.

[3] S. Kim, H.-J. Kwon, S. Lee, H. Shim, Y. Chun, W. Choi, J. Kwack, D. Han, M. Song, S. Kim, S. Mohammadi, I. Kee, S.Y. Lee, Adv. Mater. 23 (2011) 3511-3516.

[4] Y. Fan, H. Zhang, J. Chen, D. Ma, Org. Electron. 14 (2013) 1898-1902.

[5] A. Chutinan, K. Ishihara, T. Asano, M. Fujita, S. Noda, Org. Electron. 6 (2005) 3-9.

[6] V. Bulović, V.B. Khalfin, G. Gu, P.E. Burrows, D.Z. Garbuzov, S.R. Forrest, Phys. Rev. B 58 (1998) 3730-3740.

[7] L.H. Smith, J.A.E. Wasey, I.D.W. Samuel, W.L. Barnes, Adv. Funct. Mater. 15 (2005) $1839-1844$.

[8] S. Nowy, B.C. Krummacher, J. Frischeisen, N.A. Reinke, W. Brütting, J. Appl. Phys. 104 (2008) 123109.

[9] O. Lozan, M. Perrin, B. Ea-Kim, J.M. Rampnoux, S. Dilhaire, P. Lalanne, Phys. Rev. Lett. 112 (2014) 193903.

[10] D. Yokoyama, J. Mater. Chem. 21 (2011) 19187-19202.

[11] M. Flämmich, M.C. Gather, N. Danz, D. Michaelis, A.H. Bräuer, K. Meerholz, A. Tünnermann, Org. Electron. 11 (2010) 1039-1046.

[12] R. Mac Ciarnain, D. Michaelis, T. Wehlus, A.F. Rausch, N. Danz, A. Bräuer A. Tünnermann, Org. Electron. 44 (2017) 115-119.

[13] M. Fujita, K. Ishihara, T. Ueno, T. Asano, S. Noda, H. Ohata, T. Tsuji, H. Nakada, N. Shimoji, Jpn. J. Appl. Phys. 44 (2005) 3669-3677.

[14] J.M. Ziebarth, A.K. Saafir, S. Fan, M.D. McGehee, Adv. Funct. Mater. 14 (2004) $451-456$.

[15] B.J. Matterson, J.M. Lupton, A.F. Safonov, M.G. Salt, W.L. Barnes, I.D.W. Samuel, Adv. Mater. 13 (2001) 123-127.

[16] P.A. Hobson, J.A.E. Wasey, I. Sage, W.L. Barnes, IEEE J. Sel. Top. Quantum Electron. 8 (2002) 378-386.

[17] S.M. Jeong, F. Araoka, Y. Machida, K. Ishikawa, H. Takezoe, S. Nishimura, G. Suzaki, Appl. Phys. Lett. 92 (2008) 083307.

[18] K. Ishihara, M. Fujita, I. Matsubara, T. Asano, S. Noda, H. Ohata, A. Hirasawa, H. Nakada, N. Shimoji, Appl. Phys. Lett. 90 (2007) 111114.

[19] V. Reboud, A.Z. Khokhar, B. Sepulveda, D. Dudek, T. Kehoe, J. Cuffe, N. Kehagias, M. Lira-Cantu, N. Gadegaard, V. Grasso, V. Lambertini, C.M. Sotomayor Torres, Nanoscale 4 (2012) 3495-3500.

[20] Y. Luo, L. Wang, Y. Ding, L. Li, J. Shi, Opt. Lett. 38 (2013) 2394-2396.

[21] Y. Luo, C. Wang, L. Wang, Y. Ding, L. Li, B. Wei, J. Zhang, ACS Appl. Mater. Interfaces 6 (2014) 10213-10219.

[22] W. Youn, J. Lee, M. Xu, R. Singh, F. So, ACS Appl. Mater. Interfaces 7 (2015) 8974-8978.

[23] J.H. Hwang, H.J. Lee, Y.S. Shim, C.H. Park, S.-G. Jung, K.N. Kim, Y.W. Park, B.K. Ju, Nanoscale 7 (2015) 2723-2728.

[24] H.-D. Li, C.-S. Hsu, F.-M. Zhan, Y.-C. Chao, ACS Appl. Mater. Interfaces 7 (2015) $7462-7465$.

[25] Y. Sun, S.R. Forrest, Nat. Phot. 2 (2008) 483-487.

[26] S. Möller, S.R. Forrest, J. Appl. Phys. 91 (2002) 3324-3327.

[27] Y. Sun, S.R. Forrest, J. Appl. Phys. 100 (2006) 073106.

[28] E. Wrzesniewski, S.-H. Eom, W. Cao, W.T. Hammond, S. Lee, E.P. Douglas, J. Xue, Small 8 (2012) 2647-2651.

[29] D.H. Hwang, O.T. Kwon, W.J. Lee, J.W. Hong, T.W. Kim, Phys. Status Solidi A 211 (2014) 1773-1777.

[30] N. Kaihovirta, C. Larsen, L. Edman, ACS Appl. Mater. Interfaces 6 (2014) 2940-2947.

[31] S. Reineke, F. Lindner, G. Schwartz, N. Seidler, K. Walzer, B. Lussem, K. Leo, Nature 459 (2009) 234-238.

[32] W. Zhu, X. Wu, W. Sun, L. Sun, K. Guo, M. Tang, P.A. Zhou, Org. Electron. 15 (2014) 1113-1119.

[33] J.Y. Kim, C.W. Joo, J. Lee, J.-C. Woo, J.-Y. Oh, N.S. Baek, H.Y. Chu, J.-I. Lee, RSC Adv. 5 (2015) 8415-8421.

[34] C. Lee, J.-J. Kim, Small 9 (2013) 3858-3863.
[35] F. Galeotti, W. Mróz, G. Scavia, C. Botta, Org. Electron 14 (2013) 212-218.

[36] G. Widawski, M. Rawiso, B. Francois, Nature 369 (1994) 387-389.

[37] P. Escalé, L. Rubatat, L. Billon, M. Save, Eur. Polym. J. 48 (2012) 1001-1025.

[38] M. Hernandez-Guerrero, M.H. Stenzel, Polym. Chem. 3 (2012) 563-577.

[39] A. Muñoz-Bonilla, M. Fernández-García, J. Rodríguez-Hernández, Prog. Polym. Sci. 39 (2014) 510-554.

[40] FUJIFILM developed a set-up to prepare $30 * 20 \mathrm{~cm} 2$ honeycomb films. Iwanaga, $\mathrm{H}$. S., K.; Yamazaki, H. Fabrication and application of honeycomb film. FujiFilm Research and Development 2009, No. 54.

[41] H. Yamazaki, K. Ito, H. Yabu, M. Shimomura, Soft Matter 10 (2014) 2741-2747.

[42] T.-W. Koh, J.A. Spechler, K.M. Lee, C.B. Arnold, B.P. Rand, ACS Photon 2 (2015) $1366-1372$.

[43] D. Gigmes, J. Vinas, N. Chagneux, C. Lefay, T.N.T. Phan, T. Trimaille, P.-E. Dufils, Y. Guillaneuf, G. Carrot, F. Boué, D. Bertin, Controlled/living Radical Polymerization: Progress in RAFT, DT, NMP \& OMRP, (2009), pp. 245-262.

[44] P. Lacroix-Desmazes, J.-F. Lutz, F. Chauvin, R. Severac, B. Boutevin, Macromolecules 34 (2001) 8866-8871.

[45] T. Nishikawa, R. Ookura, J. Nishida, K. Arai, J. Hayashi, N. Kurono, T. Sawadaishi, M. Hara, M. Shimomura, Langmuir 18 (2002) 5734-5740.

[46] P. Escale, M. Save, A. Lapp, L. Rubatat, L. Billon, Soft Matter 6 (2010) 3202-3210.

[47] L. Billon, M. Manguian, V. Pellerin, M. Joubert, O. Eterradossi, H. Garay, Macromolecules 42 (2009) 345-356.

[48] P. Escalé, W. Van Camp, F. DuPrez, L. Rubatat, L. Billon, M. Save, Polym. Chem. 4 (2013) 4710-4717.

[49] A. Bertrand, A. Bousquet, C. Dagron-Lartigau, L. Billon, Chem. Commun. 52 (2016) 9562-9565.

[50] E. Ji, V. Pellerin, F. Ehrenfeld, A. Laffore, A. Bousquet, L. Billon, Chem. Commun. 53 (2017) 1876-1879.

[51] P. Escalé, M. Save, L. Billon, J. Ruokolainen, L. Rubatat, Soft Matter 12 (2016) $790-797$.

[52] X. Yang, X. Xu, G. Zhou, J. Mater. Chem. C 3 (2015) 913-944.

[53] W.-C. Chen, C.-S. Lee, Q.-X. Tong, J. Mater. Chem. C 3 (2015) 10957-10963.

[54] M. Zhu, C. Yang, Chem. Soc. Rev. 42 (2013) 4963-4976.

[55] K.S. Yook, J.Y. Lee, Adv. Mater. 24 (2012) 3169-3190.

[56] J.-F. Chang, Y.-S. Huang, P.-T. Chen, R.-L. Kao, X.-Y. Lai, C.-C. Chen, C.-C. Lee, Opt Express 23 (2015) 14695-14706.

[57] Y. Setoguchi, C. Adachi, J. Appl. Phys. 108 (2010) 064516.

[58] F. Dumur, S. Reculusa, M. Mruczkiewicz, M. Perrin, L. Vignau, S. Fasquel, Opt. Exp. 24 (2016) 27184-27198.

[59] M. Perrin, Opt. Exp. 24 (2016) 27137-27151.

[60] L. Peres, V. Vigneras, S. Fasquel, Sol. Energy Mater. Sol. C 117 (2013) 239-245.

[61] S. Fan, J.D. Joannopoulos, Phys. Rev. A 65 (2002) 235112.

[62] L. Novotny, B. Hecht, Principles of Nano-optics, second ed., Cambridge University Press, Cambridge, 2012.

[63] M. Flämmich, J. Frischeisen, S.D. Setz, D. Michaelis, B.C. Krummacher, T.D. Schmidt, W. Brütting, N. Danz, Org. Elect. 12 (2011) 1663-1668.

[64] https://www.fluxim.com/.

[65] J.C. Bernède, S. Houari, D. Nguyen, P.Y. Jouan, A. Khelil, A. Mokrani, L. Cattin, P. Predeep, Phys. Status Solidi A 7 (2012) 1291-1297.

[66] Y. Zhang, S.-L. Lai, Q.-X. Tong, M.-Y. Chan, T.-W. Ng, Z.-C. Wen, G.-Q. Zhang, S.T. Lee, H.-L. Kwonge, C.-S. Lee, J. Mater. Chem. 21 (2011) 8206-8214.

[67] J.-F. Chang, Y.-S. Huang, P.-T. Chen, R.-L. Kao, X.-Y. Lai, C.-C. Chen, C.-C. Lee, Opt. Express 23 (2015) 14695-14706.

[68] A. Magri, P. Friederich, B. Schäfer, V. Fattori, X. Sun, T. Strunk, V. Meded, L.E. Hueso, W. Wenzel, M. Ruben, Beilstein J. Nanotechnol. 6 (2015) 1107-1115.

[69] L. Peres, V. Vigneras, S. Fasquel, Opt. Exp. 22 (2014) A1229-A1236.

[70] X.-B. Shi, M. Qian, Z.-K. Wang, L.-S. Liao, J. Mater. Chem. C 3 (2015) 1666-1671.

[71] T. Lei, J. Pei, J. Mater. Chem. 22 (2012) 785-798.

[72] J.H. Jou, W.B. Wang, S.Z. Chen, J.J. Shyue, M.F. Hsu, C.W. Lin, S.M. Shen, C.J. Wang, C.P. Liu, C.T. Chen, M.F. Wu, S.W. Liu, J. Mater. Chem. 20 (2010) 8411-8416.

[73] J.H. Jou, S. Kumar, A. Agrawal, T.S. Lia, S. Sahoo, J. Mater. Chem. C 3 (2015) 2974-3002.

[74] X.-B. Shi, M. Qian, Z.-K. Wang, L.-S. Liao, Appl. Phys. Lett. 106 (2015) 223301.

[75] J. Yang, M. Perrin, P. Lalanne, Phys. Rev. X 5 (2015) 021008. 